\title{
Early age at first childbirth and skilled birth attendance during delivery among young women in sub-Saharan Africa
}

\author{
Eugene Budu' ${ }^{1}$ Vijay Kumar Chattu ${ }^{2,3}$, Bright Opoku Ahinkorah ${ }^{4}$, Abdul-Aziz Seidu ${ }^{5,6^{*}}$ (D), Aliu Mohammed ${ }^{7}$, \\ Justice Kanor Tetteh ${ }^{1}$, Francis Arthur-Holmes ${ }^{8}$, Collins Adu ${ }^{9}$ and Sanni Yaya ${ }^{10,11}$
}

\begin{abstract}
Background: Despite the numerous policy interventions targeted at preventing early age at first childbirth globally, the prevalence of adolescent childbirth remains high. Meanwhile, skilled birth attendance is considered essential in preventing childbirth-related complications and deaths among adolescent mothers. Therefore, we estimated the prevalence of early age at first childbirth and skilled birth attendance among young women in sub-Saharan Africa and investigated the association between them.
\end{abstract}

Methods: Demographic and Health Survey data of 29 sub-Saharan African countries was utilized. Skilled birth attendance and age at first birth were the outcome and the key explanatory variables in this study respectively. Overall, a total of 52,875 young women aged 20-24years were included in our study. A multilevel binary logistic regression analysis was performed and the results presented as crude and adjusted odds ratios at 95\% confidence interval.

Results: Approximately $73 \%$ of young women had their first birth when they were less than 20 years with Chad having the highest proportion (85.7\%) and Rwanda recording the lowest (43.3\%). The average proportion of those who had skilled assistance during delivery in the 29 sub-Saharan African countries was $75.3 \%$ and this ranged from $38.4 \%$ in Chad to 93.7\% in Rwanda. Young women who had their first birth at the age of 20-24 were more likely to have skilled birth attendance during delivery $(\mathrm{aOR}=2.4, \mathrm{Cl}=2.24-2.53)$ than those who had their first birth before 20 years.

Conclusion: Early age at first childbirth has been found to be associated with low skilled assistance during delivery. These findings re-emphasize the need for sub-Saharan African countries to implement programs that will sensitize and encourage the patronage of skilled birth attendance among young women in order to reduce complications and maternal mortalities. The lower likelihood of skilled birth attendance among young women who had their first birth when they were adolescents could mean that this cohort of young women face some barriers in accessing maternal healthcare services.

Keywords: Age at first birth, Skilled birth attendance, Young women, Sub-Saharan Africa, Global health, Demographic and health surveys original author(s) and the source, provide a link to the Creative Commons licence, and indicate if changes were made. The images or other third party material in this article are included in the article's Creative Commons licence, unless indicated otherwise in a credit line to the material. If material is not included in the article's Creative Commons licence and your intended use is not permitted by statutory regulation or exceeds the permitted use, you will need to obtain permission directly from the copyright holder. To view a copy of this licence, visit http://creativecommons.org/licenses/by/4.0/. The Creative Commons Public Domain Dedication waiver (http://creativeco mmons.org/publicdomain/zero/1.0/) applies to the data made available in this article, unless otherwise stated in a credit line to the data. 


\section{Background}

Despite the numerous policy interventions aimed at preventing adolescent childbearing in many countries across the world, the prevalence of adolescent pregnancy and childbirth remains high [1-3]. Adolescent childbearing has been defined as birth that occurs among adolescents aged 10-19 [4]. In 2015, for example, approximately 19.4 million adolescent girls aged 10-19 years, gave birth, and 580,000 of them were aged 10-14 [4]. Most of these adolescent births occur in less developed countries, especially in sub-Saharan Africa (SSA) [5, 6]. Besides, childbearing related complications and delivery are reported to be the major cause of mortality among adolescent girls (aged 15-19) in the world [2, 3].

In SSA, an estimated 570 adolescent girls die each year due to maternal complications compared to 22 in Europe, 61 in the Americas, 77 in the Western Pacific, 130 in Southeast Asia, and 430 in the Eastern Mediterranean [7]. Again, children born to adolescent mothers have a higher risk of health complications and mortality than those born to older women $[5,8]$. It is also reported that adolescent girls have higher odds of complicated pregnancy outcomes than older women [5]. In relation to this, Grønvik and FossgardSandøy [8] reported that adolescent girls in SSA have a higher risk for prenatal and maternal mortality, low birth weight, eclampsia and preterm delivery. Other complications associated with adolescent childbearing include haemorrhage [4], systemic infections, puerperal endometritis, and increased risk for caesarean sections $[7,9]$.

Available evidence suggests that skilled birth attendance (SBA) is an important maternal health service that reduces adverse pregnancy outcomes among childbearing women and minimises post-delivery complications $[4,10]$. Therefore, increasing the proportion of skilled birth attendance is one of the surest ways of ending preventable maternal deaths in SSA and reducing the global maternal mortality rate to less than 70 per 100,000 live births by 2030 [SDG 3.1] [4, 11]. However, the utilization of skilled deliveries remains relatively low among adolescent mothers in most sub-Saharan African countries [12, 13] Mekonnen et al. [14] estimated that the prevalence of skilled delivery among adolescent mothers in SSA ranged from $10 \%$ in Ethiopia to $72 \%$ in Guinea.

Previous studies have reported that skilled birth delivery in SSA is associated with factors such as age, parity, wealth quintile [13], level of education, antenatal care attendance, access to electronic media [15], and rural/ urban residence $[15,16]$. Other factors include the distance from the health facility, male involvement, and mother's knowledge of pregnancy risk factors [17]. In Ghana, for example, Nuamah et al. [13] reported that older mothers ( $>34$ years) had higher odds of SBA during delivery than younger women ( $<24$ years). In Ethiopia, women who have access to television or those attending antenatal care at least 4 times have higher odds of SBA [15]. Similar studies conducted previously in SSA were mostly conducted among women aged 15-49years and did not specifically focus on adolescent girls $[13,15,17]$. However, few studies that focused on adolescent childbearing mostly investigated maternal services utilization such as SBA, antenatal care, and postnatal care [14, 18, 19].

Considering the negative effects of early childbearing on maternal healthcare services utilization $[14,20$, 21], it is important to understand how early age at first birth affects the utilization of SBA among young women in SSA, especially because early childbearing could have long term effect on SBA use. Therefore, we estimated the prevalence of early age at first childbirth and skilled birth attendance among young women in sub-Saharan Africa and. We also investigated the relationship between them. This study's findings will help stakeholders including health authorities to develop interventions and health programs to improve SBA among pregnant adolescent in SSA.

\section{Methods}

\section{Data source}

Demographic and Health Surveys (DHS) data of 29 sub-Saharan African countries were used for the study (Table 1). Specifically, data from the birth recode files were considered. The DHS is conducted in over 85 lowand middle-income countries and they are nationally representative. The DHS looks at important markers such as SBA [22]. A two-stage stratified sampling technique is used for the nationwide survey and this makes the data representative of each country. The sampling procedure employed for the surveys have been well documented in literature [23]. Young women (aged 20-24) totaling 52,875 with complete information on all the variables of interest were included in our study. Strengthening the Reporting of Observational Studies in Epidemiology' (STROBE) statement was used as a guide to help in writing the manuscript [24]. The dataset is available and free for download at https://dhsprogram.com/data/availabledatasets.cfm

\section{Definition of variables \\ Outcome variable}

This study used assistance during delivery as the main outcome variable. Assistance during delivery was obtained from the question, "Who assisted [NAME] during delivery?". Responses to the question was categorized into "Traditional Birth Attendants/Others (traditional health volunteer, community/village health volunteer, 
Table 1 Description of the study sample

\begin{tabular}{|c|c|c|c|c|}
\hline Countries & Year of survey & Women aged $20-24$ years & Women with a birth history & $\begin{array}{l}\text { Women with } \\
\text { complete } \\
\text { cases }\end{array}$ \\
\hline 1. Angola & 2015-16 & 2988 & 2323 & 2323 \\
\hline 2. Burkina Faso & 2018 & 3267 & 2529 & 2528 \\
\hline 3. Benin & 2017-18 & 2880 & 1986 & 1985 \\
\hline 4. Burundi & 2016-17 & 3210 & 1805 & 1805 \\
\hline 5. Congo DR & 2018 & 3649 & 2608 & 2601 \\
\hline 6. Congo & 2014-15 & 1983 & 1472 & 1472 \\
\hline 7. Cote d'Ivoire & 2012 & 1924 & 1310 & 1304 \\
\hline 8. Cameroon & 2011-12 & 3283 & 1550 & 1549 \\
\hline 9. Ethiopia & 2013-14 & 2728 & 1543 & 1543 \\
\hline 10. Gabon & 2011-12 & 1599 & 1020 & 1020 \\
\hline 11. Ghana & 2016 & 1591 & 773 & 773 \\
\hline 12. Gambia & 2012 & 2099 & 1202 & 1202 \\
\hline 13. Guinea & 2013 & 1729 & 1167 & 1167 \\
\hline 14. Kenya & 2014 & 5662 & 3747 & 3742 \\
\hline 15. Comoros & 2018 & 968 & 391 & 391 \\
\hline 16. Liberia & 2014 & 1615 & 1316 & 1316 \\
\hline 17. Lesotho & 2014 & 1306 & 817 & 818 \\
\hline 18. Mali & 2013 & 1871 & 1496 & 1496 \\
\hline 19. Malawi & 2015-16 & 5083 & 4091 & 4091 \\
\hline 20. Nigeria & 2018 & 6749 & 4351 & 4351 \\
\hline 21. Namibia & 2013 & 1761 & 1010 & 1009 \\
\hline 22. Rwanda & 2018 & 2427 & 1180 & 1180 \\
\hline 23. Sierra Leone & 2014-15 & 2629 & 1945 & 1945 \\
\hline 24. Senegal & 2010-11 & 3174 & 1739 & 1739 \\
\hline 25. Chad & 2013 & 3016 & 2517 & 2503 \\
\hline 26. Togo & 2013-14 & 1640 & 922 & 922 \\
\hline 27. Uganda & 2016 & 3765 & 2850 & 2850 \\
\hline 28. Zambia & 2018 & 2700 & 2040 & 2040 \\
\hline 29. Zimbabwe & 2015 & 1674 & 1204 & 1204 \\
\hline Total & & 78,063 & 52,906 & 52,875 \\
\hline
\end{tabular}

neighbors/friends/relatives and other people and "skilled birth attendants (doctor, nurse, auxiliary midwife, or nurse/midwife).

\section{Independent variables}

The study's primary explanatory variable was "age at first birth," which was obtained from the question, "how old were you when you first gave birth?". For this study, the responses were re-coded into "early age at first birth" $=1$ and "late age at first birth" $=2$, where "early age at first birth" and "late age at first birth" represented the respondents who gave birth between age 10-19 and age 20-24 respectively.

\section{Control variables}

Five individual and five contextual level variables were the focus of this study. The individual-level variables comprised education (no education, primary and secondary/higher), marital status (not married, married, cohabiting, widowed, divorced/separated), parity (one birth, two births, three births and four or more births), mass media exposure included exposure to the newspaper, radio and television (no and yes), and religion (Christianity, Islam and others). The contextual level variables were wealth index (poorest, poorer, middle, richer and richest), sex of household head (male and female), community literacy level - the proportion of women in the community who can read and write (low, middle and high), community socio-economic status - the proportion of women in the community 
with richest wealth quintile (low, medium and high), place of residence (urban and rural) and sub-region (West Africa, East Africa, Central Africa and Southern Africa). The sub-Saharan African countries included in this study were Ghana, Mali, Burkina Faso, Cote d'Ivoire, Benin, Senegal, Zimbabwe, Gambia, Namibia, Guinea, Nigeria, Gabon, Sierra Leone, Togo, Burundi, Cameroon, Uganda, Ethiopia, Kenya, Comoros, Malawi, Rwanda, Zambia, Angola, Congo DR, Congo, Liberia, Chad, and Lesotho [25]. The variables of this study were derived with respect to their theoretical relevance, parsimony and practical significance with SBA during delivery [20, 26-29].

\section{Statistical analyses}

The data analysis was executed with Stata version 14.0. The analysis was done in three phases. The first phase comprised the calculation of the prevalence of SBA (Fig. 1) and early age at first childbirth (Fig. 2). The second phase involved a bivariate analysis that estimated SBA prevalence across the independent and control variables with their significance levels (Table 2). Using the variance inflation factor (VIF), a test for multicollinearity was then carried out and the results showed no evidence of high collinearity (Mean VIF $=1.49$, Maximum VIF $=2.46$, and Minimum VIF $=1.02$ ). The test for collinearity was conducted to check for a high correlation among the explanatory variables. From Table 2, all variables that showed statistical significance were included in a two-level multilevel logistic regression analysis that had five models. The first model (Model O) was the empty model that showed the variance in SBA in the absence of the explanatory variables. Model I had only age at first birth and SBA. Model II contained the individual-level variables and SBA. Model III had the contextual level variables and SBA. The final model (Model IV) contained age at first birth, the control variables and SBA. The multilevel logistic regression analysis comprised fixed and random effects [30].

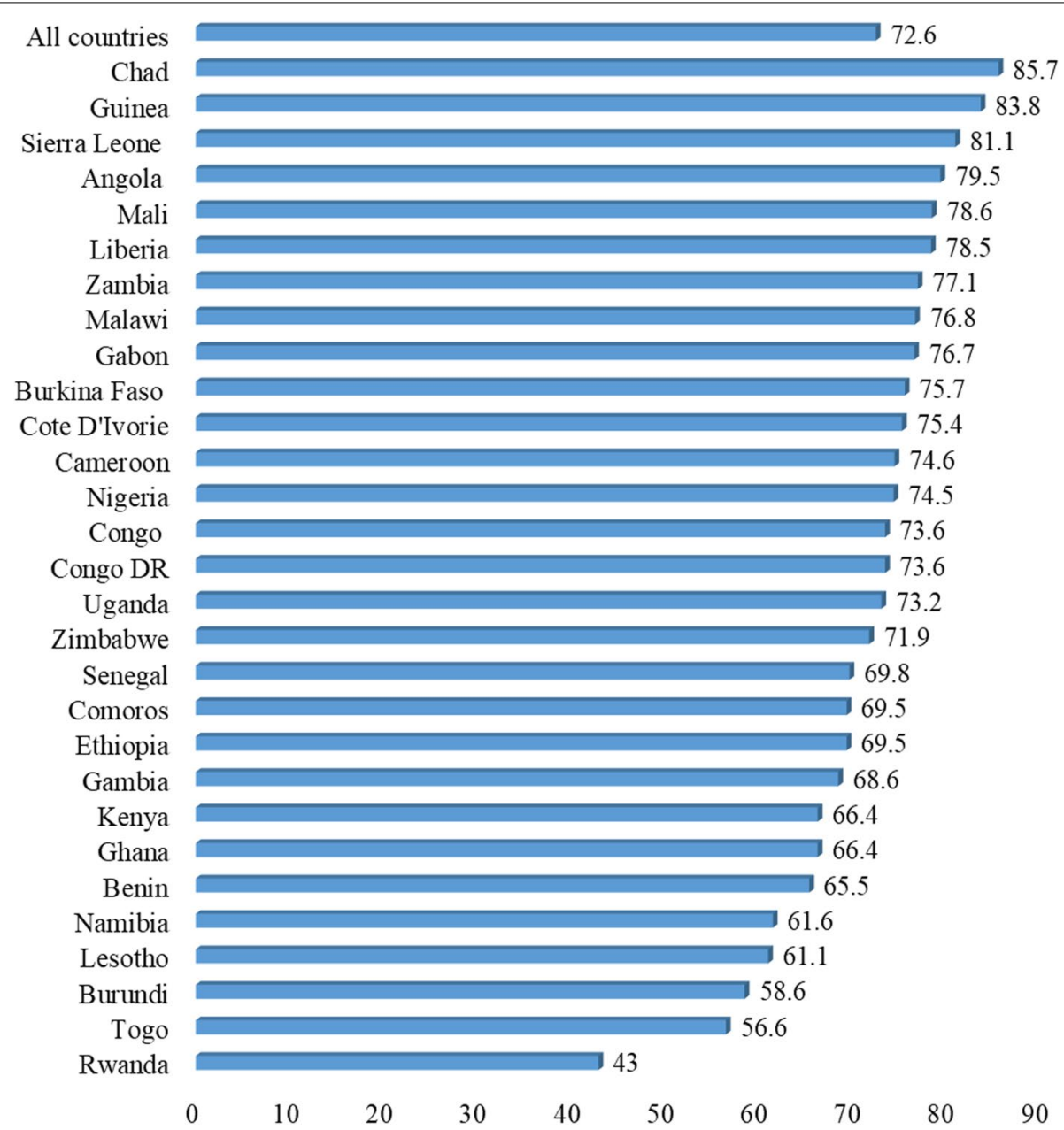

Fig. 1 Proportion of young women whose first childbirth occurred when they were adolescents in sub-Saharan Africa 


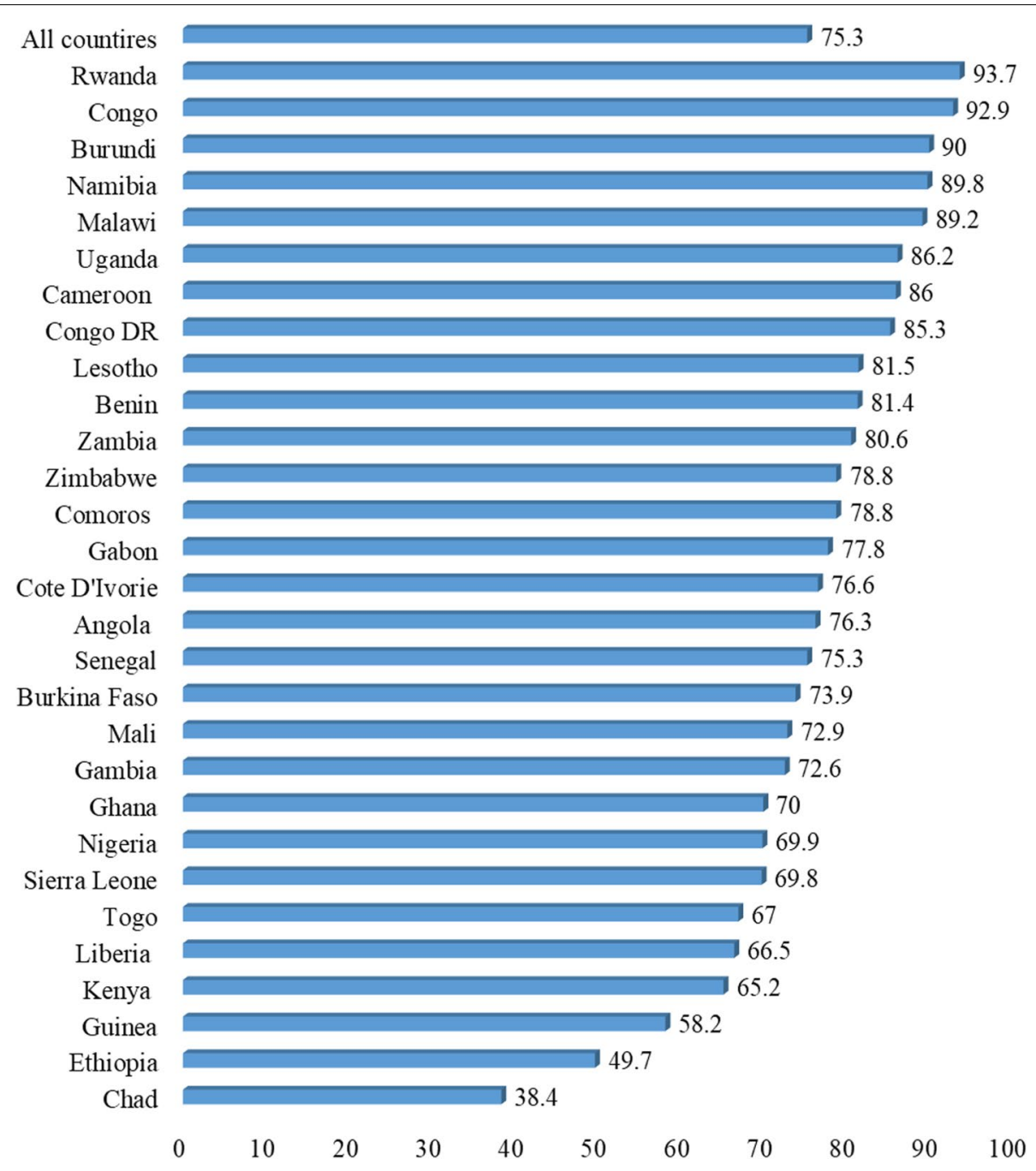

Fig. 2 Proportion of young women who had skilled assistance during delivery in sub-Saharan Africa

The purpose of different models was due to the nature of the control variables which were grouped into individual and contextual variables. We wanted to see how the inclusion of each set of variable would affect the relationship between age at first birth andSBA. In this study, fixed effects results of the model were presented as crude odds ratio (cOR) and adjusted odds ratio (aOR) whiles the random effects were examined using Intra-Cluster Correlation (ICC) [30]. The log-likelihood ratio (LLR) and Akaike's Information Criterion (AIC) tests were used for the model comparisons. In Stata, during the regression analysis, we employed the survey command (svy) to adjust for the complex sampling structure of the data. We also weighted all frequency distributions. Since this was a pooled data, the survey weight in each country's dataset was de-normalized and re-normalized based on the population sizes of the countries in the study and the new weights generated were used in the appended dataset for the analysis.

\section{Results}

Proportion of young women whose first birth occurred when they were adolescents and those who had skilled assistance during delivery in sub-Saharan Africa

Figure 1 shows the proportions of young women whose first birth occurred during adolescence in the 29 subSaharan African countries. The overall proportion of young women whose first birth occurred during adolescence was $72.6 \%$. Rwanda (43.3\%) recorded the lowest proportion of young women whose first birth occurred during adolescence, with Chad having the highest proportion (85.7\%). The majority of the countries recorded $70-80 \%$ of young women having their first birth before 20 years. 
Table 2 Distribution of skilled birth attendance during delivery by age at first birth and individual and contextual characteristics of young women in sub-Saharan Africa

\begin{tabular}{|c|c|c|c|c|}
\hline Variables & Weighted N & Weighted \% & $\begin{array}{l}\text { Skilled birth attendance } \\
\text { during delivery }\end{array}$ & $p$-value \\
\hline Age at first birth & & & & $<0.001$ \\
\hline$<20$ years & 38,380 & 72.6 & 70.9 & \\
\hline 20-24years & 14,495 & 27.4 & 87.1 & \\
\hline Level of education & & & & $<0.001$ \\
\hline No education & 15,524 & 29.4 & 61.5 & \\
\hline Primary & 18,242 & 34.5 & 77.3 & \\
\hline Secondary + & 19,109 & 36.1 & 84.7 & \\
\hline Marital status & & & & $<0.001$ \\
\hline Not married & 7388 & 14.0 & 79.3 & \\
\hline Married & 31,805 & 60.2 & 72.9 & \\
\hline Cohabiting & 9627 & 18.2 & 80.6 & \\
\hline Widowed & 286 & 0.5 & 65.1 & \\
\hline Divorced/separated & 3769 & 7.1 & 75.4 & \\
\hline Parity & & & & $<0.001$ \\
\hline One birth & 23,989 & 45.4 & 79.3 & \\
\hline Two births & 17,940 & 33.9 & 75.1 & \\
\hline Three births & 7992 & 15.1 & 68.9 & \\
\hline Four or more births & 2954 & 5.6 & 62.3 & \\
\hline Wealth index & & & & $<0.001$ \\
\hline Poorest & 10,806 & 20.4 & 64.0 & \\
\hline Poorer & 11,619 & 22.0 & 71.1 & \\
\hline Middle & 10,788 & 20.4 & 75.9 & \\
\hline Richer & 10,749 & 20.3 & 81.3 & \\
\hline Richest & 8913 & 16.9 & 86.6 & \\
\hline Mass media exposure & & & & $<0.001$ \\
\hline No & 19,341 & 36.6 & 69.6 & \\
\hline Yes & 33,534 & 63.4 & 78.7 & \\
\hline Sex of head of household & & & & 0.003 \\
\hline Male & 40,940 & 77.4 & 74.9 & \\
\hline Female & 11,935 & 22.6 & 76.8 & \\
\hline Religion & & & & $<0.001$ \\
\hline Christianity & 33,242 & 62.9 & 80.0 & \\
\hline Islam & 17,452 & 33.0 & 67.5 & \\
\hline Others & 2181 & 4.1 & 67.6 & \\
\hline Residence & & & & $<0.001$ \\
\hline Urban & 18,392 & 34.8 & 83.7 & \\
\hline Rural & 34,483 & 65.2 & 70.9 & \\
\hline Community-level literacy & & & & $<0.001$ \\
\hline Low & 18,992 & 35.9 & 66.3 & \\
\hline Medium & 17,948 & 33.9 & 77.3 & \\
\hline High & 15,935 & 30.2 & 83.9 & \\
\hline Community socio-economic level & & & & $<0.001$ \\
\hline Low & 26,349 & 49.8 & 67.6 & \\
\hline Medium & 10,142 & 19.2 & 80.0 & \\
\hline High & 16,383 & 31.0 & 84.8 & \\
\hline Sub-region & & & & $<0.001$ \\
\hline West Africa & 19,417 & 36.7 & 72.1 & \\
\hline East Africa & 21,416 & 40.5 & 79.7 & \\
\hline
\end{tabular}


Table 2 (continued)

\begin{tabular}{llll}
\hline Variables & Weighted $\mathbf{N}$ & Weighted $\%$ & $\begin{array}{l}\text { Skilled birth attendance } \\
\text { during delivery }\end{array}$ \\
\hline Central Africa & 10,215 & 19.3 & 70.5 \\
Southern Africa & 1827 & 3.5 & 86.1 \\
\hline
\end{tabular}

The average proportion of skilled assistance during delivery in SSA was $75.3 \%$, ranging from $38.4 \%$ in Chad to $93.7 \%$ in Rwanda. It is important to mention that countries like Congo (92.9\%), Burundi (90\%), Namibia (89.8\%) and Malawi (89.2\%) also recorded higher skilled assistance during delivery (see Fig. 2).

\section{Distribution of skilled birth attendance during delivery across age at first birth and individual and contextual characteristics of young women in sub-Saharan Africa} Table 2 presents the distribution of SBA during delivery across age at first birth and socio-demographic characteristics of young women in SSA. Women whose first birth occurred at age 20-24 had a higher prevalence of skilled assistance during delivery (87.1\%) than those whose first birth occurred before 20 years $(70.9 \%)$. Women in the primary (77.3\%) and secondary/higher education category $(84.7 \%)$ had a higher prevalence of skilled assistance during delivery than those without formal education. Cohabiting women $(80.9 \%)$ had the highest prevalence of skilled birth assistance in terms of marital status. Women with one parity (79.3\%) had a higher prevalence than those with four or more births (62.3\%). Also, skilled assistance during delivery was more prevalent among women in the richest $(86.6 \%)$ and richer $(81.3 \%)$ wealth quintile than those in the poorer $(71.1 \%)$ and poorest $(64.0 \%)$ wealth quintile. However, women in both male (74.9\%) and female $(76.8 \%)$ headed households had a higher prevalence of skilled assistance during delivery with a difference of $1.9 \%$. Skilled assistance during delivery was more prevalent among urban residents $(83.7 \%)$ than rural residents $(70.9 \%)$. Skilled assistance during delivery was higher among Christians (80.0\%) than Muslims (67.5\%) and women of other religions (67.6\%). Lastly, women with high community-level literacy $(83.9 \%)$ and socioeconomic status (84.8\%) had a higher prevalence of skilled assistance during delivery than those with low and medium community level literacy and socio-economic status (Table 2).

\section{Fixed and random effects of results on the association between early age at first birth and skilled birth attendance among young women}

Table 3 shows the fixed and random effects of the association between early age at first birth and SBA among young women. In terms of the random effects results, the clustering of the primary sampling units (PSUs) in "model O[Null model]" was responsible for significant differences in the odds of SBA $(\sigma 2=0.14,95 \%$ CI 0.11 0.17 ). Model $O$ showed that $4 \%$ of the total variation in SBA was attributed to the variance between clusters $(\mathrm{ICC}=0.04)$. The between-cluster variance remained the same $(\mathrm{ICC}=0.04)$ in Model I, rounding off to 2 decimal places . From Model I, the ICC increased to $6 \%$ in Model II but decreased to $4 \%$ in Model III. It then increased to $6 \%$ in Model IV, where all the independent variables (both individual and community level variables) were considered. This indicates that differences in the PSUs' clustering account for the variations in SBA. The highest log-likelihood (- 27,255.173) and the lowest AIC $(54,560.35)$ were used to determine the best fit model (See Table 3). The fixed results of the analysis are also shown in Table 3. In Model I, women who gave birth at the age of 20-24 were 2.7 times more likely to have SBA during delivery than those with first birth before 20 years $\quad(\mathrm{OR}=2.69, \mathrm{CI}=2.55-2.84)$. After controlling for all the individual and community level factors in Model IV, women whose first birth occurred at the age of 20-24 still had higher odds of SBA during delivery $(\mathrm{aOR}=2.37, \mathrm{CI}=2.23-2.5)$ than those with first birth before 20 years. Level of education, marital status, parity, religion, wealth index, sex of household head, community literacy level, community socio-economic status, and place of residence showed statistically significant associations with SBA during delivery (Table 3).

\section{Discussion}

The prevalence of early age at first childbirth and SBA among young women in SSA was investigated in this study. We also investigated the relationship between early age at first birth and SBA among young women in SSA. On average, $75.3 \%$ of births among young women in SSA were supervised by skilled birth attendants with Chad (38.4\%) and Rwanda (93.7\%) recording the lowest and highest prevalence respectively. Although the 
Table 3 Fixed and random effects results on the association between adolescent childbearing and skilled birth attendance

\begin{tabular}{|c|c|c|c|c|c|}
\hline Variables & Null model & $\begin{array}{l}\text { Model I } \\
\text { AOR[95\%Cl] }\end{array}$ & $\begin{array}{l}\text { Model II } \\
\text { AOR[95\%Cl] }\end{array}$ & $\begin{array}{l}\text { Model III } \\
\text { AOR[95\%Cl] }\end{array}$ & $\begin{array}{l}\text { Model IV } \\
\text { AOR[95\%Cl] }\end{array}$ \\
\hline \multicolumn{6}{|l|}{ Age at first birth } \\
\hline$<20$ years & & 1 & & & 1 \\
\hline 20-24years & & $2.69^{* * * *}(2.55-2.84)$ & & & $2.37^{* * *}(2.23-2.52)$ \\
\hline \multicolumn{6}{|l|}{ Level of education } \\
\hline No education & & & $0.37^{* * *}(0.34-0.39)$ & & $0.50^{* * *}(0.47-0.54)$ \\
\hline Primary & & & $0.67^{* * *}(0.63-0.70)$ & & $0.85^{* * *}(0.80-0.90)$ \\
\hline Secondary + & & & 1 & & 1 \\
\hline \multicolumn{6}{|l|}{ Marital status } \\
\hline Not married & & & $0.85^{* * *}(0.79-0.91)$ & & $0.91^{* *}(0.84-0.98)$ \\
\hline Married & & & 1 & & 1 \\
\hline Cohabiting & & & $1.17^{* * *}(1.10-1.25)$ & & $1.31^{* * *}(1.22-1.40)$ \\
\hline Widowed & & & $0.64^{* * * *}(0.49-0.82)$ & & $0.68^{* *}(0.52-0.88)$ \\
\hline Divorced/separated & & & $0.82^{* * *}(0.75-0.89)$ & & $0.91^{*}(0.83-0.99)$ \\
\hline \multicolumn{6}{|l|}{ Parity } \\
\hline One birth & & & 1 & & 1 \\
\hline Two births & & & $0.91^{* * *}(0.87-0.96)$ & & $1.25^{* * *}(1.19-1.32)$ \\
\hline Three births & & & $0.76^{* * * *}(0.72-0.81)$ & & $1.19^{* * *}(1.11-1.27)$ \\
\hline Four or more births & & & $0.59^{* * *}(0.54-0.64)$ & & $0.98(0.90-1.07)$ \\
\hline \multicolumn{6}{|l|}{ Mass media exposure } \\
\hline No & & & $0.72^{* * *}(0.69-0.75)$ & & $0.96(0.91-1.00)$ \\
\hline Yes & & & 1 & & 1 \\
\hline \multicolumn{6}{|l|}{ Religion } \\
\hline Christianity & & & 1 & & 1 \\
\hline Islam & & & $0.69^{* * *}(0.65-0.72)$ & & $0.58^{* * *}(0.55-0.618)$ \\
\hline Others & & & $0.64^{* * *}(0.58-0.71)$ & & $0.64^{* * *}(0.58-0.71)$ \\
\hline \multicolumn{6}{|l|}{ Wealth index } \\
\hline Poorest & & & & $0.73^{* * * *}(0.69-0.77)$ & $0.78^{* * * *}(0.74-0.83)$ \\
\hline Poorer & & & & 1 & 1 \\
\hline Middle & & & & $1.12^{* * * *}(1.05-1.19)$ & $1.10^{* *}(1.03-1.17)$ \\
\hline Richer & & & & $1.22^{* * *}(1.13-1.31)$ & $1.20^{* * *}(1.12-1.30)$ \\
\hline Richest & & & & $1.37^{* * * *}(1.24-1.51)$ & $1.33^{* * *}(1.20-1.48)$ \\
\hline \multicolumn{6}{|c|}{ Sex of head of household } \\
\hline Male & & & & 1 & 1 \\
\hline Female & & & & $0.91^{* * * *}(0.87-0.96)$ & $0.91^{* * * *}(0.86-0.96)$ \\
\hline \multicolumn{6}{|c|}{ Community literacy level } \\
\hline Low & & & & 1 & 1 \\
\hline Medium & & & & $1.54^{* * *}(1.47-1.62)$ & $1.21^{* * *}(1.15-1.28)$ \\
\hline High & & & & $1.77^{* * * *}(1.65-1.90)$ & $1.21^{* * *}(1.12-1.31)$ \\
\hline \multicolumn{6}{|c|}{ Community socioeconomic level } \\
\hline Low & & & & 1 & 1 \\
\hline Medium & & & & $1.39^{* * * *}(1.31-1.48)$ & $1.43^{* * *}(1.34-1.53)$ \\
\hline High & & & & $1.28^{* * *}(1.15-1.40)$ & $1.39^{* * *}(1.28-1.52)$ \\
\hline \multicolumn{6}{|l|}{ Place of residence } \\
\hline Urban & & & & $1.23^{* * * *}(1.15-1.31)$ & $1.18^{* * *}(1.11-1.26)$ \\
\hline Rural & & & & 1 & 1 \\
\hline \multicolumn{6}{|l|}{ Sub-region } \\
\hline West Africa & & & & $0.69^{* * * *}(0.64-0.70)$ & $1.17^{* * *}(1.10-1.25)$ \\
\hline East Africa & & & & 1 & 1 \\
\hline Central Africa & & & & $0.60^{* * *}(0.56-0.63)$ & $0.69^{* * *}(0.64-0.73)$ \\
\hline
\end{tabular}


Table 3 (continued)

\begin{tabular}{|c|c|c|c|c|c|}
\hline Variables & Null model & $\begin{array}{l}\text { Model I } \\
\text { AOR[95\%Cl] }\end{array}$ & $\begin{array}{l}\text { Model II } \\
\text { AOR[95\%Cl] }\end{array}$ & $\begin{array}{l}\text { Model III } \\
\text { AOR[95\%Cl] }\end{array}$ & $\begin{array}{l}\text { Model IV } \\
\text { AOR[95\%Cl] }\end{array}$ \\
\hline South Africa & & & & $1.58^{* * * *}(1.38-1.82)$ & $1.28^{* * *}(1.11-1.47)$ \\
\hline \multicolumn{6}{|l|}{ Random effect result } \\
\hline PSU variance $(95 \% \mathrm{Cl})$ & $0.14(0.11-0.17)$ & $0.14(0.12-0.18)$ & $0.20(0.16-0.25)$ & $0.15(0.12-0.19)$ & $0.21(0.16-0.27)$ \\
\hline ICC & 0.040297 & 0.0420914 & 0.0565033 & 0.044011 & 0.0601468 \\
\hline LR Test & $\begin{array}{l}\text { Chi- } \\
\text { square }=281.90, \\
p<0.001\end{array}$ & $\begin{array}{l}\text { Chi-square =281.97, } \\
p<0.001\end{array}$ & $\begin{array}{l}\text { Chi-square }=293.22, \\
p<0.001\end{array}$ & $\begin{array}{l}\text { Chi-square }=244.75 \\
p<0.001\end{array}$ & $\begin{array}{l}\text { Chi-square }=259.45 \\
p<0.001\end{array}$ \\
\hline Wald chi-square & & $1339.03^{* * *}$ & $3268.46^{* * *}$ & $2971.7^{* * *}$ & $4802.36^{* * *}$ \\
\hline \multicolumn{6}{|l|}{ Model fitness } \\
\hline Log-likelihood & $-30,023.153$ & $-29,255.109$ & $-28,252.061$ & $-28,650.877$ & $-27,116.869$ \\
\hline $\mathrm{AlC}$ & $60,050.31$ & $58,516.22$ & $56,532.12$ & $56,803.06$ & $54,289.74$ \\
\hline $\mathrm{N}$ & 52,875 & 52,875 & 52,875 & 52,875 & 52,875 \\
\hline Number of clusters & 1580 & 1580 & 1580 & 1580 & 1580 \\
\hline
\end{tabular}

Exponentiated coefficients; $95 \%$ confidence intervals in brackets

${ }^{*} p<0.05,{ }^{* *} p<0.01,{ }^{* * *} p<0.001$

prevalence of $75.3 \%$ in SSA was higher than the average of $61 \%$ reported between 2014 and 2019 for less developed countries, it was still lower than the average of $99 \%$ in developed countries [31]. Again, the prevalence of early age at first childbirth from this study was highest in Chad (85.7\%) and lowest in Rwanda (43\%). The high prevalence of early age at first birth in Chad could explain why SBA in the country is low. This could be that many of the young women whose first childbirth occurred when they were adolescents may face barriers accessing SBA . Such barriers may include cost of maternal healthcare services, stigma, and negative attitude of healthcare providers $[14,20]$.

Young women in SSA who had their first birth at the age of 20-24 were 2.7 times more likely to have SBA during delivery than those who had first birth before 20 years. A similar result was reported in 2016 by the Family Health Division of Ghana Health Service, where younger adolescents (10-14yrs) were less likely to utilize SBA than older adolescents (15-19). In contrast with previous findings in Nigeria [32] and Mali [33] where no statistical significance was found between adolescents' age and maternal healthcare utilization, our finding supports results that were reported in Pakistan [34]. The possible reason for this finding could be the fear of stigmatization, devaluation, stereotyping, and shaming young pregnant adolescents receive at health facilities [35-37]. In many sub-Saharan African countries, negative social stigma and attitudes towards adolescent pregnancy are deeply rooted in cultural values making it difficult for even some trained health personnel to change them [35, 38, 39]. This makes many young adolescents feel reluctant to access antenatal care and have SBA during delivery. Also, it is reported that women's autonomy in healthcare decision making increases with age, which affects maternal services utilization [20, 40-43].

Our findings showed that education had a significant relationship with SBA utilization. The lower the education, the less likelihood of SBA utilization and vice versa. Women with no formal education and women who lived in communities with low literacy levels had lower odds of SBA than those with secondary/higher levels of education and includes young women who lived in communities with medium or high literacy levels. This supports previous research output in Nepal [44], Pakistan [35], Namibia [45], Nigeria [46], Gambia [47], and Ethiopia [48-50]. Ameyaw et al. [51] assert that education increases young women's exposure to information, knowledge, occupation with high income and access to mass media, which subsequently informs their healthcare decisions and utilization of maternal health services. Young women with secondary/higher education levels may be more empowered and informed about the importance of SBA and be more willing to utilize skilled birth delivery services. However, it is argued that community literacy level leads to high uptake and sharing of accurate maternal health information that influences positive maternal healthcare decision-making among adolescents [1].

Our study supports findings of previous studies $[52,53]$ that showed that women with no mass media exposure had lower odds of SBA during delivery. Mass media, particularly radio and television stations should air health programs to educate people about the pressing health problems in the community. However, those who are exposed to these mass media outlets are more likely to 
be well informed about SBA services than those with no exposure. Studies have shown that access to mass media education positively affects one's behavior towards the utilization of health services and SBA [54].

Also, our study found that young women with two or three births in SSA had higher odds of utilizing SBA services compared with their counterparts with one birth. This finding supports previous research conducted in Pakistan and Bangladesh, where women with more than two births were more likely to utilize SBA than women one birth $[35,55]$. This could be related with the experience obtained when SBA is utilized for first and subsequent births. For instance, a woman who experienced complications during her first childbirth or had obstetric difficulty may choose to always engage the services of an SBA during subsequent deliveries [56].

Pregnant adolescents residing in urban areas were found to have higher odds of SBA during delivery compared to those in rural areas. This finding highlights the inequalities in access to SBA among young women in SSA and supports other studies in Pakistan [35], Namibia [45], and Ethiopia [48, 57], where young women in urban areas had higher odds of using SBA during delivery. The health facilities in the urban centers might be reasonable for higher utilization of SBA during delivery in SSA. Shorter distance to health facilities in urban centers and better roads and transportation networks, and an increased exposure to mass media and health information may increase the tendency for young women and adolescents to utilize SBA during delivery [48]. In contrast, rural residents might be more influenced by traditional practices.

Furthermore, religion was found to predict the odds of SBA utilization in SSA. Muslim women had lower odds of using SBA during deliveries than Christian women. This corroborates with Ganle's [58] study findings in Ghana which reported that maternal health services utilization including SBA were low among Muslim women in Northern Ghana. As empirical evidence suggests, religion is a significant predictor of maternal healthcare utilization $[59,60]$. There are several factors that could possibly explain why maternal health services utilization among Muslim women is low. One of the reasons could be that religion and culture often interconnect. As argued in the literature, cultural beliefs that affect SBA and maternal healthcare utilization negatively dominate among a religious group [61, 62].

Our findings also show that women in the poorest wealth quintile and women in communities with low socioeconomic levels had lower odds of SBA than women in the middle, richer and richest quintiles and communities with medium to high socio economic status. In contrast, a Nigerian study finding reported no statistical significance between SBA and the socio-economic/ wealth quintile of married adolescents [20]. This study's finding, therefore, corroborates with results from a crosssectional study in Ghana where household wealth was significant in predicting SBA utilization among women [59]. The disparities in the findings could be due to how data was collected on wealth or socioeconomic status in each study setting. This study finding re-emphasizes the need for sub-Saharan African countries to bridge economic inequality that predisposes many disadvantaged adolescents to poor maternal health outcomes, including non-use of SBA.

\section{Strengths and limitations}

One of the strengths of this study is its nationally representativeness. Nationally representative data across 29 sub-Saharan African countries were used. The findings therefore can be generalized to all young women in SSA. Again, data collection techniques and methods used followed best practices and they were used by experienced and well-trained data collectors. This led to a high response rate. Also, the study used advanced statistical models for its analysis in conformance with accepted scientific practices. However, despite these strengths, country-specific findings may not be the same as what has been found across the 29 countries. Again due to the study design, this study cannot generate causal interpretation and the findings and relationships between variables reported from this study may also differ over time.

\section{Conclusions}

Early age at first childbirth has been found to be associated with low skilled assistance during delivery. These findings re-emphasize the need for sub-Saharan African countries to implement programs that will increase the utilization of SBA among young women. We recommend that efforts towards increasing girl child education and ending stigmatization of pregnant adolescents in SSA should be intensified. There is also the need for community sensitisation in the various countries on the effects of adolescent childbearing. Healthcare providers could also educate adolescent girls about contraceptive usage. Further studies should explore the lived experiences of adolescent mothers in accessing SBA in SSA to obtain indepth information on the challenges adolescents face in accessing SBA services.

\section{Abbreviations}

AOR: Adjusted Odds Ratio; AIC: Information Criterion; Cl: Confidence Interval: DHS: Demographic and Health Survey; SBA: Skilled Birth Attendants; SSA: SubSaharan Africa; ICC: Intra-Cluster Correlation; VIF: Variance inflation factor. 


\section{Acknowledgements}

We acknowledge Measure DHS for providing us with the data.

\section{Authors' contributions}

EB conceived the study. EB, BOA and AS analyzed the data. EB, VKC, BOA, AS, $A M, J K T, F A-H, C A$ and $S Y$ drafted the first draft of the manuscript. EB, VKC, BOA, AS, AM, JKT, FA-H, CA and SY conducted the final review and approval of the final version of this manuscript. The final manuscript was read and approved by all authors.

\section{Funding}

No specific grant from funding agencies either in the public, commercial, or not-for-profit sectors was received for this research.

\section{Availability of data and materials}

This link provides free access to the data set used in the study: https://dhspr ogram.com/data/dataset/

\section{Declarations}

\section{Ethics approval and consent to participate}

No further approval was required for this study. This is because the study employed secondary data for its analysis and this secondary data is freely available to the general public. More information in relation to the DHS data usage and ethical standards are available at http://goo.gl/ny8T6X.

\section{Consent for publication}

Not applicable.

\section{Competing interests}

The authors declare that they have no competing interests.

\section{Author details}

${ }^{1}$ Department of Population and Health, University of Cape Coast, Cape Coast, Ghana. ${ }^{2}$ Department of Public Health, Saveetha Medical College and Hospitals, SIMATS, Saveetha University, Chennai, TN 600077, India. ${ }^{3}$ Department of Community Medicine, Faculty of Medicine, Datta Meghe Institute of Medical Sciences (Deemed University), Wardha, MS 442107, India. ${ }^{4}$ School of Public Health, Faculty of Health, University of Technology Sydney, Sydney, Australia. ${ }^{5}$ College of Public Health, Medical and Veterinary Sciences, James Cook University, Townsville, Australia. ${ }^{6}$ Centre For Gender and Advocacy, Takoradi Technical University, P.O.Box 256, Takoradi, Ghana. ${ }^{7}$ Department of Health, Physical Education and Recreation, University of Cape Coast, Cape Coast, Ghana. ${ }^{8}$ Department of Sociology and Social Policy, Lingnan University, 8 Castle Peak Road, Tuen Mun, Hong Kong. ${ }^{9}$ Department of Health Promotion, Education and Disability Studies, Kwame Nkrumah University of Science and Technology, Kumasi, Ghana. ${ }^{10}$ School of International Development and Global Studies, University of Ottawa, Ottawa, Canada. ${ }^{11}$ The George Institute for Global Health, Imperial College London, London, UK.

Received: 2 December 2020 Accepted: 19 November 2021 Published online: 14 December 2021

\section{References}

1. Ahinkorah BO, Seidu AA, Appiah F, et al. Individual and community-level factors associated with modern contraceptive use among adolescent girls and young women in Mali: a mixed effects multilevel analysis of the 2018 Mali demographic and health survey. Contracept Reprod Med. 2020;5:27 https://doi.org/10.1186/s40834-020-00132-7.

2. UNFPA. Adolescent pregnancy. 2017. Retrieved from https://www.unfpa. org/adolescentpregnancy.

3. World Health Organisation. Adolescent pregnancy. 2020. Retrieved from https://www.who.int/news-room/fact-sheets/detail/adolescent-pregn ancy.

4. Kassebaum NJ, Barber RM, Bhutta ZA, Dandona L, Gething PW, Hay SI, et al. Global, regional, and national levels of maternal mortality, 1990-2015: a systematic analysis for the Global Burden of Disease Study 2015. Lancet. 2016:388(10053):1775-812.
5. Finlay JE, Özaltin E, Canning D. The association of maternal age with infant mortality, child anthropometric failure, diarrhoea and anaemia for first births: evidence from 55 low-and middle-income countries. BM Open. 2011;1(2):1-24

6. Kassa GM, Arowojolu AO, Odukogbe AA, Yalew AW. Prevalence and determinants of adolescent pregnancy in Africa: a systematic review and meta analysis. Reprod Health. 2018;15(1):195.

7. Nove A, Matthews Z, Neal S, Camacho AV. Maternal mortality in adolescents compared with women of other ages: evidence from 144 countries. Lancet Glob Health. 2014;2(3):e155-64.

8. GrønvikT, FossgardSandøy I. Complications associated with adolescent childbearing in Sub-Saharan Africa: A systematic literature review and meta-analysis. PLoS One. 2018;13(9):e0204327.

9. Ganchimeg T, Ota E, Morisaki N, Laopaiboon M, Lumbiganon P, Zhang J, et al. Pregnancy and childbirth outcomes among adolescent mothers: a World Health Organization multicountry study. BJOG. 2014;121:40-8.

10. Vieira C, Portela A, Miller T, Coast E, Leone T, Marston C. Increasing the use of skilled health personnel where traditional birth attendants were providers of childbirth care: a systematic review. PLoS One. 2012;7(10):e47946.

11. World Health Organization. Trends in maternal mortality 2000 to 2017 : estimates by WHO, UNICEF, UNFPA, World Bank Group and the United Nations Population Division. Geneva; 2019. Retrieved from https://apps. who.int/iris/handle/10665/327595

12. Adegoke AA, Van Den Broek N. Skilled birth attendance-lessons learnt. BJOG. 2009;116:33-40.

13. Nuamah GB, Agyei-Baffour P, Mensah KA, Boateng D, Quansah DY, Dobin $D$, et al. Access and utilization of maternal healthcare in a rural district in the forest belt of Ghana. BMC Pregnancy Childbirth. 2019;19(1):6.

14. Mekonnen T, Dune T, Perz J. Maternal health service utilisation of adolescent women in sub-Saharan Africa: a systematic scoping review. BMC Pregnancy Childbirth. 2019;19(1):366.

15. Mengesha ZB, Biks GA, Ayele TA, Tessema GA, Koye DN. Determinants of skilled attendance for delivery in Northwest Ethiopia: a community based nested case control study. BMC Public Health. 2013;13(1):1-6.

16. Crowe S, Utley M, Costello A, Pagel C. How many births in sub-Saharan Africa and South Asia will not be attended by a skilled birth attendant between 2011 and 2015? BMC Pregnancy Childbirth. 2012;12(1):4.

17. Mpembeni RN, Killewo JZ, Leshabari MT, Massawe SN, Jahn A, Mushi D, et al. Use pattern of maternal health services and determinants of skilled care during delivery in Southern Tanzania: implications for achievement of MDG-5 targets. BMC Pregnancy Childbirth. 2007;7(1):1-7.

18. Banke-Thomas OE, Banke-Thomas AO, Ameh CA. Factors influencing utilisation of maternal health services by adolescent mothers in Low-and middle-income countries: a systematic review. BMC Pregnancy Childbirth. 2017;17(1):65

19. Kurth F, Belard S, Mombo-Ngoma G, Schuster K, Adegnika AA, Bouyou-Akotet MK, et al. Adolescence as risk factor for adverse pregnancy outcome in Central Africa-a cross-sectional study. PLoS One. 2010;5(12):e14367.

20. Olakunde BO, Adeyinka DA, Mavegam BO, Olakunde OA, Yahaya HB, Ajiboye $O A$, et al. Factors associated with skilled attendants at birth among married adolescent girls in Nigeria: evidence from the multiple Indicator cluster survey, 2016/2017. Int Health. 2019;11(6):545-50 https://doi.org/ 10.1093/inthealth/ihz017.

21. Erasmus MO, Knight L, Dutton J. Barriers to accessing maternal health care amongst pregnant adolescents in South Africa: a qualitative study. Int J Public Health. 2020;65:469-76.

22. Corsi DJ, Neuman M, Finlay JE, Subramanian SV. Demographic and health surveys: a profile. Int J Epidemiol. 2012;41(6):1602-13.

23. Aliaga A, Ruilin R. Cluster optimal sample size for demographic and health surveys. In7th International Conference on Teaching StatisticsICOTS, vol. 7; 2006. p. 2-7.

24. Von Elm E, Altman DG, Egger M, Pocock SJ, Gøtzsche PC, Vandenbroucke JP. The strengthening the reporting of observational studies in epidemiology (STROBE) statement: quidelines for reporting observational studies. Ann Intern Med. 2007;147(8):573-7.

25. United Nations 1999, Standard country or area codes for statistics use, 1999 (Revision 4),viewed May 23 2020, <https://unstats.un.org/unsd/ publications/catalogue?select|D=109> 
26. Mezmur M, Navaneetham K, Letamo G, Bariagaber H. Individual, household and contextual factors associated with skilled delivery care in Ethiopia: evidence from Ethiopian demographic and health surveys. PLoS One. 2017;12(9):e0184688.

27. Nyongesa C, Xu X, Hall JJ, Macharia WM, Yego F, Hall B. Factors influencing choice of skilled birth attendance at ANC: evidence from the Kenya demographic health survey. BMC Pregnancy Childbirth. 2018;18(1):88.

28. Ameyaw EK, Dickson KS. Skilled birth attendance in Sierra Leone, Niger, and Mali: analysis of demographic and health surveys. BMC Public Health. 2002;20(1):164

29. Yaya S, Uthman OA, Amouzou A, Ekholuenetale M, Bishwajit G. Inequalities in maternal health care utilization in Benin: a population based crosssectional study. BMC Pregnancy Childbirth. 2018;18(1):194.

30. Merlo J, Wagner P, Ghith N, Leckie G. An original stepwise multilevel logistic regression analysis of discriminatory accuracy: the case of neighbourhoods and health. PLoS One. 2016;11(4):e0153778.

31. UNICEF and World Health Organization, UNICEF data: monitoring the situation of children and women. Delivery Care, October 2020. 2020. Retrieved from https://data.unicef.org/topic/maternal-health/deliverycare/. on 10/11/2020

32. Rai RK, Singh PK, Singh L. Utilization of maternal health care services among married adolescent women: insights from the Nigeria demographic and health survey, 2008. Womens Health Issues. 2012;22(4):e40714 https://doi.org/10.1016/j.whi.2012.05.001.

33. Singh PK, Singh L, Kumar C, et al. Correlates of maternal healthcare service utilisation among adolescent women in Mali: analysis of a nationally representative cross-sectional survey, 2006. J Public Health. 2013;21:1527 https://doi.org/10.1007/s10389-012-0516-9.

34. Pongpanich S, Ghaffar A, Ghaffar N, Mehmood T. Skilled birth attendance in Balochistan, Pakistan. Asian Biomed. 2017;10(1):25-34 https://doi.org/ 10.5372/1905-7415.1001.461.

35. Kola L, Bennett IM, Bhat A, et al. Stigma and utilization of treatment for adolescent perinatal depression in Ibadan Nigeria. BMC Pregnancy Childbirth. 2020;20:294. https://doi.org/10.1186/s12884-020-02970-4

36. Hall KS, Manu A, Morhe E, Dalton VK, Challa S, Loll D, et al. Bad girl and unmet family planning need among Sub-Saharan African adolescents: the role of sexual and reproductive health stigma. Qual Res Med Healthc. 2018;2(1):55-64 https://doi.org/10.4081/qrmh.2018.7062.

37. Hackett $K$, Lenters $L$, Vandermorris $A$, et al. How can engagement of adolescents in antenatal care be enhanced? Learning from the perspectives of young mothers in Ghana and Tanzania. BMC Pregnancy Childbirth. 2019:19:184. https://doi.org/10.1186/s12884-019-2326-3.

38. Ahinkorah BO, Hagan JE Jr, et al. Examining pregnancy related sociocultural factors among adolescent girls in the Komenda-Edina-EguafoAbrem municipality in the central region of Ghana: a case-control study. Front Public Health. 2019:7:93.

39. Ellis-Sloan K. Teenage mothers, stigma and their 'presentations of self'. Soc Res Online. 2014;19(1):1-3.

40. Alemayehu M, Meskele M. Health care decision making autonomy of women from rural districts of Southern Ethiopia: a community based cross-sectional study. Int J Womens Health. 2017;9:213-21 https://doi. org/10.2147/IJWH.S131139.

41. Osamor P, Grady C. Factors associated with women's health care decisionmaking autonomy: empirical evidence from Nigeria. J Biosoc Sci. 2018:50(1):70-85 https://doi.org/10.1017/S0021932017000037.

42. Haider MR, Qureshi ZP, Khan MM. Effects of women's autonomy on maternal healthcare utilization in Bangladesh: evidence from a national survey. Sex Reprod Healthcare. 2017;14:40-7. https://doi.org/10.1016/j. srhc.2017.09.002.

43. Speizer IS, Story WT, Singh K. Factors associated with institutional delivery in Ghana: the role of decision-making autonomy and community norms. BMC Pregnancy Childbirth. 2014;14(398). https://doi.org/10.1186/ s12884-014-0398-7.

44. Choulagai S, Onta NS, et al. Barriers to using skilled birth attendants' services in mid- and far-western Nepal: a cross-sectional study. BMC Int Health Hum Rights. 2013;13(49):1-9.

45. Zere E, Oluwole D, Kirigia JM, Mwikisa CN, Mbeeli T. Inequities in skilled attendance at birth in Namibia:a decomposition analysis. BMC Pregnancy Childbirth. 2011;11(34):1-10.

46. Adewemimo AW, Msuya SE, Olaniyan CT, Adegoke AA. Utilisation of skilled birth attendance in northern Nigeria: a cross-sectional survey.
Midwifery. 2014;30(1):e7-e13. https://doi.org/10.1016/j.midw.2013.09. 005.

47. Lerberg PM, Sundby J, Jammeh A, Fretheim A. Barriers to skilled birth attendance: a survey among mothers in rural Gambia. Afr J Reprod Health. 2014;18(1):35-43.

48. Alemayehu M, Mekonnen W. The prevalence of skilled birth attendant utilization and its correlates in north West Ethiopia. Biomed Res Int 2015:1-8 https://doi.org/10.1155/2015/436938.

49. Tadese F, Ali A. Determinants of use of skilled birthattendance among mothers who gave birth in the past 12months in Raya Alamata District, North East Ethiopia. Clin Mother Child Health. 2014;11(2):1-9.

50. Tarekegn SM, Lieberman LS, Giedraitis V. Determi-nants of maternal health service utilization in Ethiopia: analysisof the 2011 Ethiopian Demographic and Health Survey. BMC Pregnancy Childbirth. 2014;14(1):161.

51. Ameyaw, E. K., Tetteh, J. K., Armah-ansah, E. K., \& Aduo-adjei K. Female genital mutilation / cutting in Sierra Leone : are educated women intending to circumcise their daughters ?.2020. https://doi.org/10.1186/ s12914-020-00240-0.

52. Asfaw S, Assefa T, Tesfaye A, Mamo A. Patterns of skilled birth attendant service utilization and its determinants: a cross sectional study in southern Ethiopia. Science J Public Health. 2016;4(5):415-21. https://doi.org/10. 11648/j.sjph.20160405.18.

53. Regassa N. Antenatal and postnatal care service utilization in southern Ethiopia: a population-based study. Afr Health Sci. 2011;11(3):390-7.

54. Sznitman S, Vanable PA, Carey P, Hennessy M, Brown LK, Valois RF, et al. Using culturally sensitive media messages to reduce HIV-associated sexual behavior in high-risk African American adolescents: results from a randomized trial. J Adolesc Health. 2011;49:244-51.

55. Quayyum Z, Khan MNU, Quayyum T, Nasreen H, Chowdhury M, Ensor T. "Can community level interventions have an impact on equity and utilization of maternal health care" - evidence from rural Bangladesh. Int J Equity Health. 2013;12:22. https://doi.org/10.1186/1475-9276-12-22.

56. Yanagisawa S, Oum S, Wakai S. Determinants of skilled birth attendance in rural Cambodia. Trop Med Int Heal. 2006;11(2):238-51. [cited 2016 Nov 30]. https://doi.org/10.1111/j.1365-3156.2005.01547.x.

57. Teferra AS, Alemu FM, Woldeyohannes SM. Institutional delivery service utilization and associated factors among mothers who gave birth in the last 12 months in Sekela District, north west of Ethiopia: a community based cross sectional study. BMC Pregnancy Childbirth. 2012;12(74):1-11.

58. Ganle JK. Why Muslim women in northern Ghana do not use skilled maternal healthcare services at health facilities: a qualitative study. BMC Int Health Hum Rights. 2015;15(1):10.

59. Dickson KS, Amu H. Determinants of skilled birth attendance in the northern parts of Ghana. Adv Public Health. 2017:9102808 https://doi org/10.1155/2017/9102808

60. Fagbamigbe AF, Hurricane-Ike EO, Yusuf OB, Idemudia ES. Trends and drivers of skilled birth attendant use in Nigeria (1990-2013): policy implications for child and maternal health. Int J Women's Health. 2017;9:84353. https://doi.org/10.2147/IJWH.S137848.

61. Mukabana B, Emali V. Cultural and religious factors as predictors of uptake of skilled birth services in Lurambi sub county, KENYA -a cross sectional study. Int J Adv Res. 2019;7:2320-5407 https://doi.org/10.21474/IJAR01/ 8660 .

62. Ganle JK, Kombet ML, Baatiema L. Factors influencing the use of supervised delivery services in Garu-Tempane District, Ghana. BMC Pregnancy Childbirth. 2019;19:141 https://doi.org/10.1186/s12884-019-2295-6.

\section{Publisher's Note}

Springer Nature remains neutral with regard to jurisdictional claims in published maps and institutional affiliations. 